\title{
Transcriptome analysis of messenger RNA and long noncoding RNA related to different developmental stages of tail adipose tissues of sunite sheep
}

\section{Xige He}

Inner Mongolia Agricultural University college of food science and engineering

\section{Rihan Wu}

Inner Mongolia Agricultural University College of food science and engineering

\section{Yueying Yun}

Inner Mongolia Agricultural University college of food science and engineering

Xia Qin

Inner Mongolia Agricultural University college of food science and engineering

\section{Lu Chen}

Inner Mongolia Agricultural University college of food science and engineering

\section{Yunfei Han}

Inner Mongolia Agricultural University college of food science and engineering

\section{Jindi Wu}

Inner Mongolia Agricultural University college of food science and engineering

\section{Lina Sha}

Inner Mongolia Agricultural University college of food science and engineering

Gerelt Borjigin ( $\sim$ bor_gerelt07@imau.edu.cn )

Inner Mongolia Agricultural University college of food science and engineering

\section{Research}

Keywords: Sunite sheep, fat-tailed, transcriptome analysis, long noncoding RNA

Posted Date: December 21st, 2020

DOl: https://doi.org/10.21203/rs.3.rs-131480/v1

License: (c) (i) This work is licensed under a Creative Commons Attribution 4.0 International License. Read Full License 


\section{Abstract}

Background: Sunite sheep are a fat-tailed sheep species with a low percentage of intramuscular fat and good quality lean meat, and their tail fat can be used as a source of dietary fat by humans. To understand the potential regulatory mechanism of different growth stages of tail fat in Sunite sheep, we performed highthroughput RNA sequencing to characterize the long noncoding RNA (IncRNA) and messenger RNA (mRNA) expression profiles of the sheep tail fat at the age of 6 months, 18 months, and 30 months.

Results: A total of 223 differentially expressed genes (DEGs) and 148 differentially expressed IncRNAs were found in the tail fat of 6 -, 18 -, and 30 -month-old sheep (false discovery rate $<0.05$, |Fold Changel $\geq 2$ ). Based on the Gene Ontology and Kyoto Encyclopedia of Genes and Genomes pathway analysis, we found that fatrelated DEGs were mainly expressed at 6 months of age, and gradually decreased at 18 and 30 months of age. The target gene prediction analysis shows that most of the IncRNAs target more than 20 mRNAs as their trans-regulators (53 mRNAs at most). Further, we obtained several fat-related differentially-expressed target genes; these target genes interact with different differentially expressed IncRNAs at various ages and play an important role in the development of tail fat. Based on the DEGs and differentially expressed IncRNAs, we established three co-expression networks for each comparison group.

Conclusions: Finally, we conclude that the development of the sheep tail fat is more active during the early stage of growth and gradually decreases with the increase in age. The mutual regulation of IncRNAs and mRNAs may play a key role in this complex biological process, and our findings will provide some basic theoretical data for future studies on tail fat development of fat-tailed sheep.

\section{Background}

Adipose tissue is found in various parts of the sheep body, some of which are the subcutaneous layer under the skin, around the kidneys, within the abdominal cavity, and buttocks, especially in the fat-tailed sheep. There are several fat-tailed sheep species in China such as Sunite sheep (SS), Wuzgumuqin sheep, Wuranke Sheep, and Kazakh sheep. SS, a Mongolian sheep breed, is mainly raised in the Xilingol grassland of Inner Mongolia. These sheep are accustomed to voluntary movement and typically free-feed (or naturally graze) throughout their lives. SS is a meat breed, and the important phenotype of SS is the fat tail. As the age of SS increases, the tail fat increases continuously and reaches the weight of about $3-4.5 \mathrm{~kg}$ at 30 months of age (30M). Tail fat can be used by humans as an important source of dietary fat $[1,2]$ and provides the energy needed by the human body. As a by-product of mutton, it can also be used as a raw material for daily-use products, such as soap, cosmetics, and medicinal materials.

Adipose tissue plays a vital role in maintaining the balance of homeostatic metabolic processes in domestic animals. During severe conditions, such as food scarcity resulting from migration, drought, and winter, the tail fat can provide energy [3]. According to a previous study [1], fat-tailed sheep have a low percentage of intramuscular fat and provide good quality lean meat. In contrast, short-tailed sheep have higher intramuscular fat storage. Thus, the mechanism of tail fat deposition is worth studying. Many studies have employed RNA sequencing (RNA-seq) to explore differentially expressed genes (DEGs) in the adipose tissues in fat-tailed sheep recently. To gain a better understanding of fat deposition, Li et al. [4] performed RNA-seq of 
perirenal, subcutaneous, and tail fat tissues from Guangling Large-Tailed and Small-Tailed Han (STH) sheep to determine their transcriptome profiles. The result showed that a total of 4,131 DEGs were identified in tail fat tissue, and 49 genes were shown to be involved in the peroxisome proliferator-activated receptor (PPAR) signaling pathway, which is the key pathway to balance fat metabolism [5]. Wang et al. [6] used transcriptome sequencing to compare the transcriptome profiles of tail fat tissue between Kazak and Tibetan sheep. This study identified 646 DEGs between the two breeds, and the top two genes with the largest fold change (NELL1 and FMO3), which may be relevant to fat metabolism in adipose tissues. The adipose tissue of STH sheep and Dorset sheep were analyzed by RNA-seq technology [7]; 602 DEGs were identified in two breeds of sheep, and some of these genes were significantly enriched in the triglyceride biosynthetic process. Kang et al. [8] performed DEG analysis in three types of adipose tissue (subcutaneous, visceral, and tail) in Tan sheep and identified 1,058 DEGs. Among which, HOTAIR_2, HOTAIR_3, and SP9 were highlighted in the tail region, and could be associated with tail fat development in sheep. Further, the IncRNAs and mRNAs associated with tail fat deposition and development in Lanzhou fat-tailed sheep (long fat-tailed sheep), STH sheep ( thin-tailed sheep), and Tibetan sheep (short thin-tailed sheep) were analyzed; 407 DEGs and 68 differentially expressed (DE) IncRNAs were identified [9]. It was shown that the DEGs and target genes of DE IncRNAs were enriched in fatty acid metabolism and fatty acid elongation-related pathways through gene ontology (GO) analysis and Kyoto encyclopedia of genes and genomes (KEGG) pathway analysis, which contribute to fat deposition. Network contribution based on DE mRNA and IncRNAs shows that some DE IncRNAs (TCONS_00372767, TCONS_00171926, TCONS_00054953, and TCONS_00373007) may play an important role in tail fat deposition processes. Bakhtiarizadeh \& Salami [10] have performed the transcriptome analysis in fat-tailed (Lori-Bakhtiari) and thin-tailed (Zel) Iranian sheep breeds and identified 7 DE IncRNAs and 311 DEGs between the two breeds. Further, the target prediction analysis shows that the novel IncRNAs can regulate the expression of genes involved in lipid metabolism through cis- or transregulation. In addition, the animal quantitative trait loci database suggested 1 intronic and 6 intergenic IncRNAs as candidates of sheep fat-tail development. Transcriptome analyses were performed in specific sheep tissues to reveal the potential regulatory roles of IncRNAs, such as in the skeletal muscle [11, 12, 13], pituitary $[14,15,16]$, testis $[17,18]$, and ovaries $[19,20,21]$. However, related research on IncRNA in sheep tail fat is still lacking, including the regulation mechanism of fat deposition and related molecular pathways of tail fat development. To better understand the potential role of mRNAs and IncRNAs in fat-tailed sheep, we explored the transcriptomic differences in SS's tail fat at three different growth stages, 6 months of age (6M), 18 months of age $(18 \mathrm{M})$, and $30 \mathrm{M}$. This facilitated the characterization of the mRNA and IncRNA expression profiles in the fat tail of SS, and elucidate the molecular mechanism of fat deposition. Our findings may lay a foundation for further studies in fat-tailed sheep. In particular, our study provides some information on the mechanism of fat development in fat-tailed sheep during different growth processes, which is of great significance for the development and utilization of by-products of meat breeds of sheep.

\section{Materials And Methods}

\section{Animal and tail fat tissue collection}

Nine castrated Sunite rams were selected from three different growth stages, $6 M(n=3), 18 M(n=3)$, and 30M $(n=3)$, respectively. All sheep were raised under the same conditions, including food, water source, and 
environment. After slaughtering, adipose tissue was sampled from the tail fat (top 1/3) and cut into small pieces of $2 \mathrm{~mm} \times 2 \mathrm{~mm} \times 2 \mathrm{~mm}$ [7]. These small pieces were immediately placed into cryotube (sterile without enzyme), frozen in liquid nitrogen, and transferred to $-80^{\circ} \mathrm{C}$ until RNA extraction.

All experimental procedures were approved by the Animal Ethics Committee of the Inner Mongolia Agricultural University's Animal Experimentation Area and followed the Chinese Animal Protection Law.

\section{RNA extraction and RNA-seq}

Total RNA from the nine adipose tissue samples was extracted using Trizol reagent (Invitrogen, CA, USA) according to the manufacturer's procedure. Quantity and purity of the total RNA were analyzed with Bioanalyzer 2100 and RNA 6000 Nano LabChip Kit (Agilent, CA, USA), respectively, with RNA integrity number $>$ 7.0. Approximately $10 \mu \mathrm{g}$ of total RNA was used to deplete ribosomal RNA by following the manufacturer's instructions of the Epicentre Ribo-Zero Gold Kit (Illumina, San Diego, USA). After purification, divalent cations were applied to fragment poly $(A)$ tailor poly $(A)+$ RNA fractions into small pieces under high temperature. Then, the cleaved RNA fragments were reverse transcribed to create the final complementary DNA (cDNA) library according to the protocol for the mRNA-Seq sample preparation kit (Illumina, San Diego, USA), and the average insert size for the paired-end libraries was $300 \mathrm{bp}( \pm 50 \mathrm{bp})$. Eventually, the paired-end sequencing was performed following the vendor's recommended protocol of the Illumina Hiseq 4000.

\section{Transcripts assembly}

The FastQC (http://www.bioinformatics.babraham.ac.uk/projects/fastqc/) software was used to verify the sequence quality, and adaptor contamination, low-quality bases, and undetermined bases in the raw data were removed by the Cutadapt software [22]. The clean reads were mapped into the genome of sheep (Ovis aries v3.1) using Bowtie2 [23] and Tophat2 [24], and mapped reads were assembled using the StringTie software [25]. To reconstruct a comprehensive transcriptome, all transcriptomes from sheep samples were merged using Perl scripts. After the generation of the final transcriptome, the expression levels of all transcripts were estimated using the StringTie and R package Ballgown [26].

\section{IncRNA Identification and different expression analysis}

First, transcripts that overlapped with known mRNAs and transcripts smaller than 200 bp were excluded. Subsequently, the Coding Potential Calculator (CPC) [27] and Coding-Non-Coding Index (CNCl) software tools [28] along with Pfam database [29] were utilized to predict transcripts with coding potential. Transcripts that scored $\mathrm{CPC}<-1$ and $\mathrm{CNCl}<0$ were discarded. The remaining transcripts with class code $(i, j, 0, u, x,=)$ were considered as IncRNAs. The definition of class code is as follows: (i) a transcript falling entirely within a reference intron (intronic); (j) potentially novel isoform or fragment at least one splice junction is shared with a reference transcript; (o) generic exonic overlap with a reference transcript; (u) unknown, intergenic transcript (intergenic); (x) exonic overlap with reference on the opposite strand (antisense); (=) complete match, considered as known IncRNA. Expression levels of IncRNAs and mRNAs were calculated as fragments per kilobase of transcript per million mapped reads using the StringTie. The DE mRNAs and IncRNAs were determined with an absolute value of $\log _{2}$ (Fold Change) $\geq 1$ and false detection rate (FDR) $<0.05$ using the Ballgown [26].

\section{Target gene prediction and functional analysis of IncRNAs}


In order to explore the functions of IncRNAs, the DE IncRNAs were analyzed for target prediction. In this study, coding genes 100,000 bp upstream and downstream of the target gene were considered as the cis-target genes. The targets in trans were defined by calculating the expressed correlation with IncRNAs. Then, we performed GO and KEGG analysis of the DE IncRNA targets and mRNAs, respectively, using the in-house scripts. The significance was expressed as FDR $<0.05$.

\section{Construction of the co-expression network}

To gain a better understanding of interactions between the DEGs and DE IncRNAs, the Pearson correlation coefficient (COR) of mRNA-IncRNA co-expression network was calculated. Finally, the mRNA-IncRNA coexpression network was constructed using Cytoscape (version 3.7.2) with an absolute value of COR $\geq 0.7$.

\section{Results And Discussion}

\section{RNA-Seq analysis}

The results of the RNA-Seq reads mapping is shown in Table 1. To identify the potential function of IncRNAs in tail fat tissues, the nine cDNA libraries were sequenced using the Illumina Hiseq 4000 platform. A total of $139.82 \mathrm{G}$ raw data were generated from the nine adipose tissues. After filtering out low-quality reads, $131.61 \mathrm{G}$ valid data were obtained, and the average valid ratio (reads) was $94 \%$. In detail, the valid reads obtained were: (1) 94,550,880; 98,994,810; and 99,167,036 per fat tail tissue sample from 6M (A1, A2, and A3), (2) $96,734,688 ; 97,915,792$; and 95,384,562 per fat tail tissue sample from 18M (B1, B2, and B3), and (3) 98,530,172; 95,442,058; and 100,597,240 per fat tail tissue sample from 30M (C1, C2, and C3), respectively. The average percentage of Q20 and Q30 base was more than $99 \%$ and $98 \%$, respectively, and the percentage of the Guanine-Cytosine (GC) content of each sample on an average was $48 \%$. Above all, we indicate that results of the RNA sequencing were highly reliable, and follow-up analysis can be carried out. 
Table 1

Summary of the reads mapped to the tail adipose tissue transcriptomes

\begin{tabular}{|lllllllll|}
\hline Sample & Raw Data & & Valid Data & & $\begin{array}{l}\text { Valid } \\
\text { Ratio(reads) }\end{array}$ & Q20\% & Q30\% & $\begin{array}{l}\text { GC } \\
\text { content\% }\end{array}$ \\
\hline & Read & Base & Read & Base & & & & \\
\hline A1 & 101449274 & $15.22 \mathrm{G}$ & 94550880 & $14.18 \mathrm{G}$ & 93.20 & 99.74 & 98.48 & 48 \\
\hline A2 & 103736482 & $15.56 \mathrm{G}$ & 98994810 & $14.85 \mathrm{G}$ & 95.43 & 99.81 & 98.63 & 48 \\
\hline A3 & 105051744 & $15.76 \mathrm{G}$ & 99167036 & $14.88 \mathrm{G}$ & 94.40 & 99.77 & 98.51 & 48 \\
\hline B1 & 102382092 & $15.36 \mathrm{G}$ & 96734688 & $14.51 \mathrm{G}$ & 94.48 & 99.76 & 98.47 & 48 \\
\hline B2 & 103267850 & $15.49 \mathrm{G}$ & 97915792 & $14.69 \mathrm{G}$ & 94.82 & 99.79 & 98.64 & 49 \\
\hline B3 & 102376260 & $15.36 \mathrm{G}$ & 95384562 & $14.31 \mathrm{G}$ & 93.17 & 99.70 & 98.36 & 47 \\
\hline C1 & 105462958 & $15.82 \mathrm{G}$ & 98530172 & $14.78 \mathrm{G}$ & 93.43 & 99.70 & 98.34 & 48 \\
\hline C2 & 101700360 & $15.26 \mathrm{G}$ & 95442058 & $14.32 \mathrm{G}$ & 93.85 & 99.71 & 98.35 & 49 \\
\hline C3 & 106595358 & $15.99 \mathrm{G}$ & 100597240 & $15.09 \mathrm{G}$ & 94.37 & 99.67 & 98.37 & 47 \\
\hline
\end{tabular}

$\mathrm{A} 1, \mathrm{~A} 2$, and $\mathrm{A} 3$ are 6 months of age; B1, B2, B3 are 18 months of age; C1, C2, and C3 are 30 months of age; valid ratio (reads) $=($ valid reads $/$ raw reads $)$.

\section{Summary of IncRNA and mRNA expression}

To understand the expression profile of the IncRNAs in the tail fat tissue of SS, we identified the expression levels of the IncRNAs and compared them with the expression levels of mRNA. First, a total of 20,670 mRNAs and 6,794 IncRNAs were identified. Here, 5,722 IncRNAs were identified as novel, and the remaining 1,702 IncRNAs were identified as known, which is more than the number of IncRNAs present in chicken [30] and cattle [31] adipose tissue. According to the classification rules, we classify novel IncRNAs as 1,395 (21\%) class i, $354(5 \%)$ class j, $288(4 \%)$ class o, 3,174 (47\%) class u, $511(7 \%)$ class $x$, and 1,702 (16\%) class = as known IncRNA (Fig. 1a). The chromosome distribution of IncRNAs is shown in circos figure (Fig. 1b). We found that most of the IncRNAs were mainly enhanced in chromosomes 1, 2, and 3. Then IncRNAs and mRNAs were compared with exon number, open reading frames (ORF) length, transcript length, and expression levels. The mRNAs and IncRNAs had 9.7 and 1.8 exons on an average; $86 \%$ of IncRNAs contained 1-2 exons, and $38 \%$ of mRNAs contained more than 9 exons (Fig. 2a). The size of the ORF of IncRNAs and mRNAs are mainly concentrated in the range of $0-200$ and 0-600 amino acids, respectively (Fig. 2b). The majority of IncRNAs and mRNAs were $>1000 \mathrm{bp}$ in size, and short-range ( $\leq 300 \mathrm{bp}-600 \mathrm{bp}$ ) IncRNAs were more than mRNAs. The average length of IncRNAs and mRNAs was $3184 \mathrm{bp}$ and $1903 \mathrm{bp}$, respectively. This significant difference might be due to the quantity gap of IncRNA and mRNA under similar distribution patterns (Fig. 3a). The expression levels of IncRNA were higher than the expression levels of mRNAs (Fig. 3b), which suggests that the IncRNAs may play an important role in the development of sheep tail fat tissue.

\section{Different expression analysis}


We compared the expression profiles between any two stages ( $30 \mathrm{M}$ vs $18 \mathrm{M}, 18 \mathrm{M}$ vs $6 \mathrm{M}$, and $30 \mathrm{M}$ vs $6 \mathrm{M}$ ) using $\mid \log _{2}$ (Fold Change) $\mid \geq 1$ and FDR $<0.05$ to identify DEGs and DE IncRNAs. In the comparison between $30 \mathrm{M}$ vs $6 \mathrm{M}$, we found $377 \mathrm{DEGs}$ (167 up-regulated and 210 downregulated genes). In the $30 \mathrm{M}$ vs $18 \mathrm{M}$ group, 125 DEGs (56 upregulated and 69 downregulated genes) were obtained. In the comparison of $18 \mathrm{M}$ vs $6 \mathrm{M}, 75$ DEGs (38 upregulated and 37 downregulated) were found (Fig. 4). Furthermore, 4 DEGs were commonly expressed in the comparison groups of $30 \mathrm{M}$ vs $18 \mathrm{M}$ and $18 \mathrm{M}$ vs $6 \mathrm{M}$, including IFIT5, THBS1, ENSOARG00000004030, and ENSOARG00000018868. Sixty-eight DEGs were commonly expressed in 30M vs $6 \mathrm{M}$ and $30 \mathrm{M}$ vs $18 \mathrm{M}$, and $35 \mathrm{DEGs}$ were commonly expressed between $30 \mathrm{M}$ vs $6 \mathrm{M}$ and $18 \mathrm{M}$ vs $6 \mathrm{M}$. On the other hand, $151 \mathrm{DE}$ IncRNAs were identified in $30 \mathrm{M}$ vs $6 \mathrm{M}, 30 \mathrm{M}$ vs $18 \mathrm{M}$, and $18 \mathrm{M}$ vs $6 \mathrm{M}$. Among them, $78 \mathrm{DE}$ IncRNAs including 38 upregulated (36 novel, 2 known) and 40 downregulated (39 novel, 1 known), 71 DE IncRNAs including 30 upregulated (30 novel, 0 known) and 41 downregulated (38 novel, 3 known), 61 DE IncRNAs including 34 upregulated (33 novel, 1 known) and 27 downregulated (25 novel, 2 known), respectively (Fig. 5). Fifteen DE IncRNAs were commonly expressed in the comparison groups of $30 \mathrm{M}$ vs $18 \mathrm{M}$ and $18 \mathrm{M}$ vs $6 \mathrm{M}, 25 \mathrm{DE}$ IncRNAs were commonly expressed in $30 \mathrm{M}$ vs $6 \mathrm{M}$ and $18 \mathrm{M}$ vs $6 \mathrm{M}$, and $19 \mathrm{DE}$ IncRNAs were commonly expressed in $30 \mathrm{M}$ vs $6 \mathrm{M}$ and $30 \mathrm{M}$ vs $18 \mathrm{M}$.

\section{Functional analysis of DEGs}

The top 15 GO terms and KEGG Pathway analysis performed in DEGs of the fat tail tissue at three different growth stages are shown in the scatterplot (Fig. 6). GO terms were determined by three functions, including cellular component, biological process, and molecular function. We found that more than half of the GO terms were enriched in the biological process in the comparison groups, and the cellular component obtained the most number of genes in the three comparison groups. In the three stages, the DEGs were significantly enriched in $80 \mathrm{GO}$ terms, and several fat related functions were obtained, including fatty acid beta-oxidation, triglyceride biosynthetic process, triglyceride homeostasis, lipid homeostasis, lipid biosynthetic process, regulation of fat cell differentiation, suggesting that these functions might contribute to the development of the sheep tail fat. We found five highly expressed DEGs, namely EHHADH, LPIN1, ACACA, THRSP, and GPAT4, which were related to these functions. The previous study shows that $L P I N 1$ deficiency will lead to a significant decrease in adipose tissue and abnormal expression of adipogenic genes. Conversely, increased expression of LPIN1 in skeletal muscle or adipose tissue will promote obesity in mice [32]. EHHADHis associated with the expression of genes involved in the tricarboxylic acid cycle, mitochondrial and peroxisome fatty acid oxidation, and is indispensable for the production of medium-chain dicarboxylic acids in mice during fasting [33]. ACACA is considered to be a key regulator of fat production and a limiting factor in the synthesis of long-chain fatty acids. Acetyl-CoA can be converted to malonyl-CoA [34], which may play a key role in energy metabolism and homeostasis in sheep tail fat cells. THRSP is involved in the process of adipogenesis in rodents, and it may be a potential marker gene for bovine intramuscular fat. Studies have shown that THRSP is mainly expressed in adipocyte nuclei, intramuscular adipocytes, and related cells and expressed in mature adipocytes rather than in the early stages of adipogenesis [35]. In our study, the expression of the THRSP gene was higher in the tail adipose tissue during $6 \mathrm{M}$ and $18 \mathrm{M}$, and significantly lower at 30M. We can speculate that in the early fat tissue of sheep's tail, fat hypertrophy is mainly manifested by the increase in the number of fat cells, and as the age increases, fat hypertrophy is reflected by the increase in the volume of fat cells. In addition, there were also some highly expressed genes related to fat metabolism, such as GPAT4, ACSM1, ACSM3, ACAT1, TKT, and ECHS1. GPAT4 was reported to be responsible 
for maintaining triacylglycerol stores [36], and ACSM1, ACSM3, and ACAT1 were related to fat deposition and fatty acid metabolism [37, 38, 39]. ECHS1 was shown to be associated with the fatty acid beta-oxidation [40]. Studies have shown that TKT expression affects fatty acid oxidation and mitochondrial function [41]. On the other hand, a total of 8 KEGG pathways were significantly enriched in three different stages. They were mainly focused on metabolism processes, including Carbon metabolism, Mineral absorption, Glutathione metabolism, Butanoate metabolism, and some related amino acid metabolism. Based on the KEGG pathway analysis, those highly expressed DEGs were related to Butanoate metabolism, Fatty acid metabolism, Glycerolipid metabolism, PPAR signaling pathway, which may contribute to the fat deposition in sheep tail fat.

Based on the above analysis and further screening, we obtained several DEGs that may be related to fat tail development. We performed a hierarchical clustering analysis to show the expression patterns of these DEGs (Fig, 7). It is not difficult to find that most of the genes are active in the early months of age, especially during the $6 \mathrm{M}$, and the expression of DEGs decreased gradually with the increase in age. Therefore, we indicate that the vitality of fat development weakens with the increase of age, that is to say, the development of tail fat will be more active at the age of $6 \mathrm{M}$, but will gradually decrease at the age of $18 \mathrm{M}$ and $30 \mathrm{M}$. There is a significant difference between $6 \mathrm{M}$ and $30 \mathrm{M}$ of age. Further, the expression pattern at $18 \mathrm{M}$, as the middle month, plays the role of transitioning from high metabolic activity to low metabolic activity. However, our findings are only possible in theory, and the mechanism needs to be further identified.

\section{Target Gene Prediction and Functional Analysis}

In order to explore how IncRNA participates in regulation, we predicted DE IncRNAs based on cis- and transregulation in three different stages of the fat tail development. In our study, 148 DE IncRNAs (68 upregulated and 80 downregulated) were obtained and the target genes prediction analysis was performed in these DE IncRNAs. A total of 186,113 , and $150 \mathrm{GO}$ terms were significantly enriched in target genes of $30 \mathrm{M}$ vs $6 \mathrm{M}$, $30 \mathrm{M}$ vs $18 \mathrm{M}$, and $18 \mathrm{M}$ vs $6 \mathrm{M}$ (FDR < 0.05), respectively. The top $15 \mathrm{GO}$ terms and KEGG pathway of target genes of DE IncRNAs in the three comparison groups are shown in the scatterplot (Fig. 8). There were 5 common GO terms enriched in the three comparison groups, namely plasma membrane, extracellular exosome, membrane, extracellular, and cytoplasm. The target genes of DE IncRNAs in 30M vs 6M were significantly enriched in 4 KEGG pathways, including calcium signaling pathway, cell adhesion molecules, oxytocin signaling pathway, and tight junction. Among these DE IncRNA, only one cis-regulated target gene was obtained: MSTRG.13384. 1 targets CLDN4. We found that most of the IncRNAs were targets to more than 20 mRNAs as their trans-regulators, MSTRG.20969. 1 targets to 53 mRNAs, as the largest number in 30M vs 6M. The most commonly enriched top 5 target genes were SLC7A6 (38 DE IncRNA), CDS2 (32 DE IncRNA), CA3 (31 DE IncRNA), SLC6A2 (31 DE IncRNA), PRTG (30 DE IncRNA). These target genes were mainly enriched in cellular components, such as membrane and integral component of membrane. Previous studies have indicated that with obesity, the concentration and activity of $C A 3$ in rat adipose tissue decreased [42]. The complement and coagulation cascades are the only KEGG pathway that is significantly enriched in $30 \mathrm{M}$ vs 18M. In this comparison group, MSTRG.12899.1 and ENSOART00000028120 were connected to 38 mRNAs as the largest number in $30 \mathrm{M}$ vs $18 \mathrm{M}$, respectively. The most commonly enriched top 5 target genes were SNORA23 (29 DE IncRNA), ERICH6B (27 DE IncRNA), ENSOARG00000018868 (22 DE IncRNA), FBP2 (22 DE IncRNA), and ENSOARG00000014791 (16 DE IncRNA), among which ENSOARG00000018868 is related to 
lipid binding. In $18 \mathrm{M}$ vs $6 \mathrm{M}, M S T R G .14210 .1$ targets to $48 \mathrm{mRNAs}$ as the largest number. The most commonly enriched top 5 targets genes were HECW1 (23 DE IncRNA), CRHR2 (19 DE IncRNA), FRK (19 DE IncRNA), IFIT5 (19 DE IncRNA), and PTPRZ1 (19 DE IncRNA). Based on the GO analysis, these target genes were mainly enriched in molecular function, including ATP binding and Hippo signaling pathway, and Steroid hormone biosynthesis were obtained in KEGG analysis.

Further, we obtained several fat related DE target genes in these three comparison groups. Among these targets DEGs, some of them were regarded as common DE target genes in two comparison groups, including TRIB3, ACSM1, ACSM3, TKT, SPTB, and ASGR in $30 \mathrm{M}$ vs $6 \mathrm{M}$ and $30 \mathrm{M}$ vs $18 \mathrm{M}$, and CYP1A1 and $\angle B P$ in $30 \mathrm{M}$ vs $6 \mathrm{M}$ and $18 \mathrm{M}$ vs $6 \mathrm{M}$. Based on the $\mathrm{GO}$ analysis, these DEGs were mainly enriched in fatty acid ligase activity, fatty acid biosynthetic process, glyceraldehyde-3-phosphate biosynthetic process, negative regulation of fat cell differentiation, and some lipid related functions, such as lipid binding and lipid homeostasis. It has been reported that TRIB3 was might inhibit subcutaneous fat deposition in Large White pig, and IncRNA XLOC_064871 trans-regulates TRIB3, so XLOC_064871 might play an important role in adipocyte differentiation and fatty acid metabolism in pig [43]. CYP1A1 is only expressed at $6 \mathrm{M}$ in our study, and it was reported to be expressed in brown adipose tissue [44]. The study showed that using a specific anti- $L B P$ antibody to inhibit $\angle B P$ activity can improve the adipogenic status of fully differentiated adipocytes, which makes $\angle B P$ is a novel adipokine that might display an essential role in inflammation and obesity-associated adipose tissue dysfunction [45]. In addition, we found that the same target gene was affected by different amounts and types of DE IncRNAs at different ages. For example, in $30 \mathrm{M}$ vs $6 \mathrm{M}$ and $30 \mathrm{M}$ vs $18 \mathrm{M}, 13$ and 11 DE IncRNAs were connected to ACSM1, and there were four common IncRNA targets to ACSM1 between two comparison groups; 13 and 15 IncRNAs were connected to ACSM3, 22 and 19 IncRNAs were connected to TKT between two comparison groups, however MSTRG.3410.1 is the only one IncRNA that acts as a target to ACSM3 and TKT, which suggest that MSTRG.3410.1 may be related to the fat deposition. It could indicate that different IncRNAs with different regulation patterns may impact the target gene expression pattern and play its role in different growth stages of sheep tail fat.

\section{Co-expression network construction}

We constructed three co-expression networks based on DEGs and DE IncRNA in sheep fat tail using Cytoscape (version 3.7.2) (Fig. 9). A total of 538, 158, and 184 pairs of co-expression pairs were obtained in $30 \mathrm{M}$ vs $6 \mathrm{M}, 30 \mathrm{M}$ vs $18 \mathrm{M}$, and $18 \mathrm{M}$ vs $6 \mathrm{M}$, respectively. In the comparison of $30 \mathrm{M}$ vs $6 \mathrm{M}, 78 \mathrm{DE}$ IncRNAs connected to the 26 mRNAs, and 538 pairs of co-expression pairs were obtained (403 positively and 135 negatively correlated). There were 20 IncRNAs connected to more than 10 mRNAs. MSTRG.20969.1 and MSTRG.12518. 1 were connected to mRNA 21 and 20, respectively. In the $30 \mathrm{M}$ vs 18M, 52 DE IncRNAs connected to the 9 mRNAs, and 149 pairs (118 positively correlated and 31 negatively correlated) were obtained. ENSOARTO0000028120 and MSTRG.19382.4 were co-expressed with 7 mRNAs. In $18 \mathrm{M}$ vs $6 \mathrm{M}, 60$ DE IncRNAs connected to the 13 mRNAs, and 184 pairs (139 positively correlated and 45 negatively correlated) of co-expression pairs were obtained. MSTRG.15348.1, MSTRG.14210.1, and MSTRG.14211.1 were co-expressed with $8 \mathrm{mRNAs}$. In these two comparison groups, there were only 7 (30M vs $18 \mathrm{M}$ ), and 8 (18M vs $6 \mathrm{M})$ mRNAs connected to single IncRNA, at most. This indicate that these co-expression pairs might play a crucial role, and IncRNA may regulate the development of sheep tail fat mainly through positive correlation with multiple mRNAs. 


\section{Conclusions}

In our study, we used transcriptome analysis to explore the underlying molecular mechanism of different growth stages of SS tail fat. We identified 377 DEGs and 78 DE IncRNAs between the $30 \mathrm{M}$ vs $6 \mathrm{M}, 125 \mathrm{DEGs}$ and 71 DE IncRNAs were found between the $30 \mathrm{M}$ vs $18 \mathrm{M}$, and 75 DEGs and 61 DE IncRNAs were found between the $18 \mathrm{M}$ vs $6 \mathrm{M}$ (FDR $<0.05$ and |Fold Changel $\geq 2$ ), respectively. According to the GO and KEGG analysis of DEGs, we conclude that the fat deposition in the sheep tail may be active in the early stages of growth and gradually decrease with the increase of age, and $18 \mathrm{M}$ may be a transitional period in this process. On the other hand, IncRNA participates in the regulation of the growth and development of tail fat by targeting the mRNA. These findings could provide a better understanding of the regulatory mechanism of sheep tail fat development and provide basic theoretical data for further research.

\section{Abbreviations}

mRNA: Messenger RNA

LncRNA: Long Noncoding RNA

DEGs: Differentially Expressed Genes

DE IncRNA: Differentially Expressed IncRNA

SS: Sunite Sheep

RNA-seq: RNA Sequencing

GO: Gene Ontology

KEGG: Kyoto Encyclopedia of Genes and Genomes

6M: 6 Months of Age

18M: 18 Months of Age

30M: 30 Months of Age

FDR: False Detection Rate

\section{Declarations}

\section{Acknowledgments}

We appreciate the generous help received from the laboratory of Meat Science and Biotechnology of Inner Mongolia Agricultural University, China.

\section{Funding}


This work was supported by the China Agriculture Research System (Grant No. CARS38), the Inner Mongolia Autonomous Region Science and Technology Plan Project (2019-2022).

Declarations of interest

None.

\section{Author information}

Affiliations

College of Food Science and Engineering, Inner Mongolia Agricultural University, Hohhot 010018, China

Xige He, Yueying Yun, Xia Qin, Lu Chen, Yunfei Han, Jindi Wu, Lina Sha, Gerelt Borjigin

College of Biochemistry and Engineering, Hohhot Vocational College, Hohhot 010051, China

Rihan Wu

School of Life Science and Technology, Inner Mongolia University of Science and Technology, Baotou 014010, China

Yueying Yun

\section{Contributions}

XGH and GB designed the study. XGH, YYY, XQ, LC and YFH analyzed the data. JDW, LNS and GB provided ideas and suggestions. XGH wrote the paper. All authors read and approved the final manuscript.

Corresponding authors

Correspondence to Gerelt Borjigin.

Ethics declarations

Ethics approval and consent to participate

Not applicable.

Consent for publication

Not applicable.

Competing interests

The authors declare that they have no competing interests.

References 
1. Kashan NEJ, Azar GHM, Afzalzadeh A, Salehi A. Growth performance and carcass quality of fattening lambs from fat-tailed and tailed sheep breeds. Small Ruminant Research, 2005, 60:267-71.

2. Moradi MH, Nejati-Javaremi A, Moradi-Shahrbabak M , Dodds KG, McEwan JC. Genomic scan of selective sweeps in thin and fat tail sheep breeds for identifying of candidate regions associated with fat deposition. BMC Genetics, 2012, 13.

3. Ben Sassi-Zaidy Y, Maretto F, Charfi-Cheikhrouha F, Mohamed-Brahmi A, Cassandro M. Contribution of microsatellites markers in the clarification of the origin, genetic risk factors, and implications for conservation of Tunisian native sheep breeds. Genet Mol Res. 2016;15:15017059.

4. Li B, Qiao L, An L, Wang W, Liu J, Ren Y, et al. Transcriptome analysis of adipose tissues from two fattailed sheep breeds reveals key genes involved in fat deposition. BMC Genomics. 2018;19:338.

5. Corrales P, Vidal-Puig A, Medina-Gómez G. PPARs and Metabolic Disorders Associated with Challenged Adipose Tissue Plasticity. Int J Mol Sci. 2018;19:2124.

6. Wang X, Zhou G, Xu X, Geng R, Zhou J, Yang Y, et al. Transcriptome profile analysis of adipose tissues from fat and short-tailed sheep. Gene. 2014; 549: 252-57.

7. Miao X, Luo Q, Qin X, Guo Y, Zhao H. Genome-wide mRNA-seq profiling reveals predominant downregulation of lipid metabolic processes in adipose tissues of Small Tail Han than Dorset sheep. Biochem Biophys Res Commun. 2015;467:413-20.

8. Kang D, Zhou G, Zhou S, Zeng J, Wang X, Jiang Y, et al. Comparative transcriptome analysis reveals potentially novel roles of Homeobox genes in adipose deposition in fat-tailed sheep. Sci Rep. 2017; 7: 14491.

9. Ma L, Zhang M, Jin Y, Erdenee S, Hu L, Chen H, et al. Comparative Transcriptome Profiling of mRNA and IncRNA Related to Tail Adipose Tissues of Sheep. Front Genet. 2018; $9: 365$.

10. Bakhtiarizadeh MR, Salami SA. Identification and Expression Analysis of Long Noncoding RNAs in FatTail of Sheep Breeds. G3 (Bethesda). 2019;9: 1263-76.

11. Chao T, Ji Z, Hou L, Wang J, Zhang C, Wang G, \& Wang J. Sheep skeletal muscle transcriptome analysis reveals muscle growth regulatory IncRNAs. PeerJ. 2018;6 : e4619.

12. Li Q, Liu R, Zhao H, Di R, Lu Z, Liu E, et al. Identification and Characterization of Long Noncoding RNAs in Ovine Skeletal Muscle. Animals (Basel). 2018;8 : 127.

13. Wei C, Wu M, Wang C, Liu R, Zhao H, Yang L, et al. Long Noncoding RNA Lnc-SEMT Modulates IGF2 Expression by Sponging miR-125b to Promote Sheep Muscle Development and Growth. Cell Physiol Biochem. 2018; 49: 447-62.

14. Li X, Li C, Xu Y, Yao R, Li H, Ni W, et al. Analysis of pituitary transcriptomics indicates that IncRNAs are involved in the regulation of sheep estrus. Funct Integr Genomics. 2020; 20: 563-73.

15. Yang H, Ma J, Wang Z, Yao X, Zhao J, Zhao X, et al. Genome-Wide Analysis and Function Prediction of Long Noncoding RNAs in Sheep Pituitary Gland Associated with Sexual Maturation. Genes (Basel). 2020; 11: 320 .

16. Zheng J, Wang Z, Yang H, Yao X, Yang P, Ren C, et al. Pituitary Transcriptomic Study Reveals the Differential Regulation of IncRNAs and mRNAs Related to Prolificacy in Different FecB Genotyping Sheep. Genes (Basel). 2019; 10: 157. 
17. Yang H, Wang F, Li F, Ren C, Pang J, Wan Y, et al. Comprehensive analysis of long noncoding RNA and mRNA expression patterns in sheep testicular maturation. Biol Reprod. 2018; 99: 650-61.

18. Zhang Y, Yang H, Han L, Li F, Zhang T, Pang J, et al. Long noncoding RNA expression profile changes associated with dietary energy in the sheep testis during sexual maturation. Sci Rep. 2017; 7: 5180.

19. Feng X, Li F, Wang F, Zhang G, Pang J, Ren C, et al. Genome-wide differential expression profiling of mRNAs and IncRNAs associated with prolificacy in Hu sheep. Biosci Rep. 2018; 38: BSR20171350.

20. Miao X, Luo Q, Zhao H, Qin X. Co-expression analysis and identification of fecundity-related long noncoding RNAs in sheep ovaries. Sci Rep. 2016; 6: 39398.

21. Miao X, Luo Q, Zhao H, Qin X. Ovarian transcriptomic study reveals the differential regulation of miRNAs and IncRNAs related to fecundity in different sheep. Sci Rep. 2016; 6: 35299.

22. Martin M . Cutadapt removes adapter sequences from high-throughput sequencing reads. Embnet Journal, 2011, 17.

23. Langmead B, Salzberg SL. Fast gapped-read alignment with Bowtie 2. Nat Methods. 2012; 9: $357-59$.

24. Kim D, Pertea G, Trapnell C, Pimentel H, Kelley R, Salzberg SL. TopHat2: accurate alignment of transcriptomes in the presence of insertions, deletions and gene fusions. Genome Biol. 2013; 14: R36.

25. Pertea M, Pertea GM, Antonescu CM, Chang TC, Mendell JT, Salzberg SL. StringTie enables improved reconstruction of a transcriptome from RNA-seq reads. Nat Biotechnol. 2015; 33: 290-95.

26. Frazee AC, Pertea G, Jaffe AE, Langmead B, Salzberg SL, Leek JT. Ballgown bridges the gap between transcriptome assembly and expression analysis. Nat Biotechnol. 2015; 33: 243-46.

27. Kong L, Zhang Y, Ye ZQ, Liu XQ, Zhao SQ, Wei L, Gao G. CPC: assess the protein-coding potential of transcripts using sequence features and support vector machine. Nucleic Acids Res. 2007; 35.

28. Sun L, Luo H, Bu D, Zhao G, Yu K, Zhang C, et al. Utilizing sequence intrinsic composition to classify protein-coding and long non-coding transcripts. Nucleic Acids Res. 2013; 41: e166.

29. Punta M, Coggill PC, Eberhardt RY, Mistry J, Tate J, Boursnell C, et al. The Pfam protein families database. Nucleic Acids Res. 2012; 40 (Database issue): D290-D301.

30. Muret K, Klopp C, Wucher V, Esquerré D, Legeai F, Lecerf F, et al. Long noncoding RNA repertoire in chicken liver and adipose tissue. Genet Sel Evol. 2017; 49: 6.

31. Jiang R, Li H, Huang Y, Lan X, Lei C, Chen H. Transcriptome profiling of IncRNA related to fat tissues of Qinchuan cattle. Gene. 2020; 742: 144587.

32. He XP, Xu XW, Zhao SH, Fan B, Yu M, Zhu MJ, et al. Investigation of Lpin1 as a candidate gene for fat deposition in pigs. Mol Biol Rep. 2009; 36: 1175-80.

33. Houten SM, Denis S, Argmann CA, Jia Y, Ferdinandusse S, Reddy JK, Wanders RJ. et al. Peroxisomal Lbifunctional enzyme (Ehhadh) is essential for the production of medium-chain dicarboxylic acids. J Lipid Res. 2012; 53: 1296-1303.

34. Pena RN, Noguera JL, García-Santana MJ, González E, Tejeda JF, Ros-Freixedes R, Ibáñez-Escriche N. et al. Five genomic regions have a major impact on fat composition in Iberian pigs. Sci Rep. 2019; 9: 2031.

35. Schering L, Albrecht E, Komolka K, Kühn C, Maak S. Increased expression of thyroid hormone responsive protein (THRSP) is the result but not the cause of higher intramuscular fat content in cattle. Int J Biol Sci. 
2017; 13: 532-44.

36. Cooper DE, Grevengoed TJ, Klett EL, Coleman RA. Glycerol-3-phosphate Acyltransferase Isoform-4 (GPAT4) Limits Oxidation of Exogenous Fatty Acids in Brown Adipocytes. J Biol Chem. 2015; 290 : $15112-20$.

37. Berton MP, Fonseca LF, Gimenez DF, Utembergue BL, Cesar AS, Coutinho LL, et al. Gene expression profile of intramuscular muscle in Nellore cattle with extreme values of fatty acid. BMC Genomics. 2016; 17: 972.

38. Guo B, Kongsuwan K, Greenwood PL, Zhou G, Zhang W, Dalrymple BP. A gene expression estimator of intramuscular fat percentage for use in both cattle and sheep. J Anim Sci Biotechnol. 2014; 5: 35.

39. Huang W, Guo Y, Du W, Zhang X, Li A, Miao X. Global transcriptome analysis identifies differentially expressed genes related to lipid metabolism in Wagyu and Holstein cattle. Sci Rep. 2017; 7: 5278.

40. Peng M, Han J, Li L, Ma H. Suppression of fat deposition in broiler chickens by (-)-hydroxycitric acid supplementation: A proteomics perspective. Sci Rep. 2016; 6: 32580.

41. Tian N, Liu Q, Li Y, Tong L, Lu Y, Zhu Y, et al. Transketolase Deficiency in Adipose Tissues Protects Mice From Diet-Induced Obesity by Promoting Lipolysis. Diabetes. 2020; 69: 1355-67.

42. Wang HL, Zhu ZM, Wang H, Yang SL, Zhao SH, Li K. Molecular characterization and association analysis of porcine CA3. Cytogenet Genome Res. 2006; 115: 129-33.

43. Huang W, Zhang X, Li A, Xie L, Miao X. Differential regulation of mRNAs and IncRNAs related to lipid metabolism in two pig breeds. Oncotarget. 2017; 8: 87539-53.

44. Galván N, Teske DE, Zhou G, Moorthy B, MacWilliams PS, Czuprynski CJ, Jefcoate CR. Induction of CYP1A1 and CYP1B1 in liver and lung by benzo(a)pyrene and 7,12-d imethylbenz(a)anthracene do not affect distribution of polycyclic hydrocarbons to target tissue: role of AhR and CYP1B1 in bone marrow cytotoxicity. Toxicol Appl Pharmacol. 2005; 202: 244-57.

45. Moreno-Navarrete JM, Escoté X, Ortega F, Serino M, Campbell M, Michalski MC, et al. A role for adipocytederived lipopolysaccharide-binding protein in inflammation- and obesity-associated adipose tissue dysfunction. Diabetologia. 2013; 56: 2524-37.

\section{Figures}


a

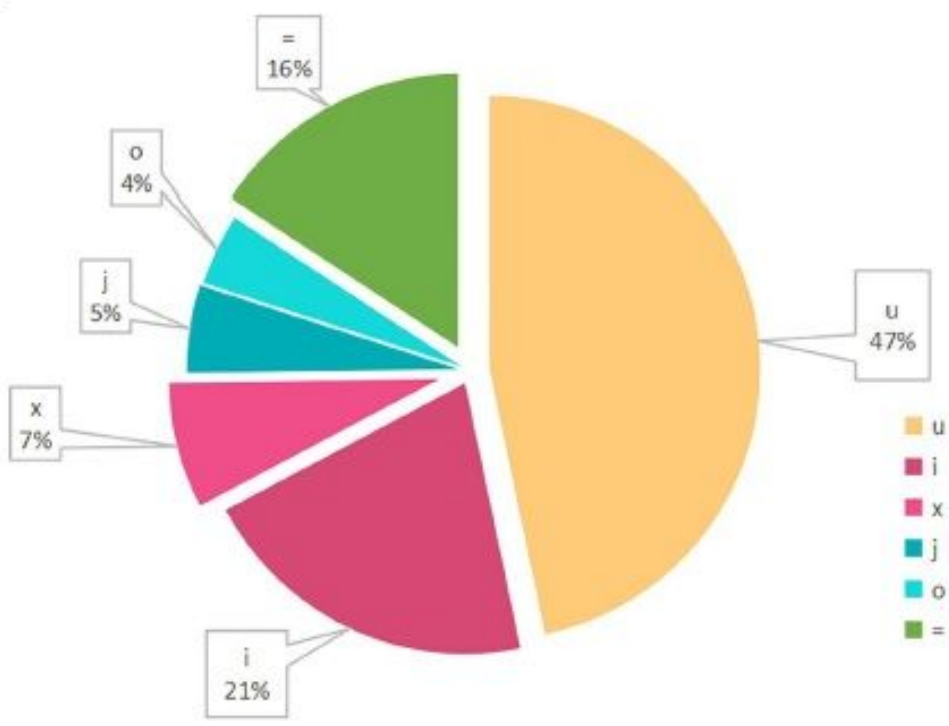

b

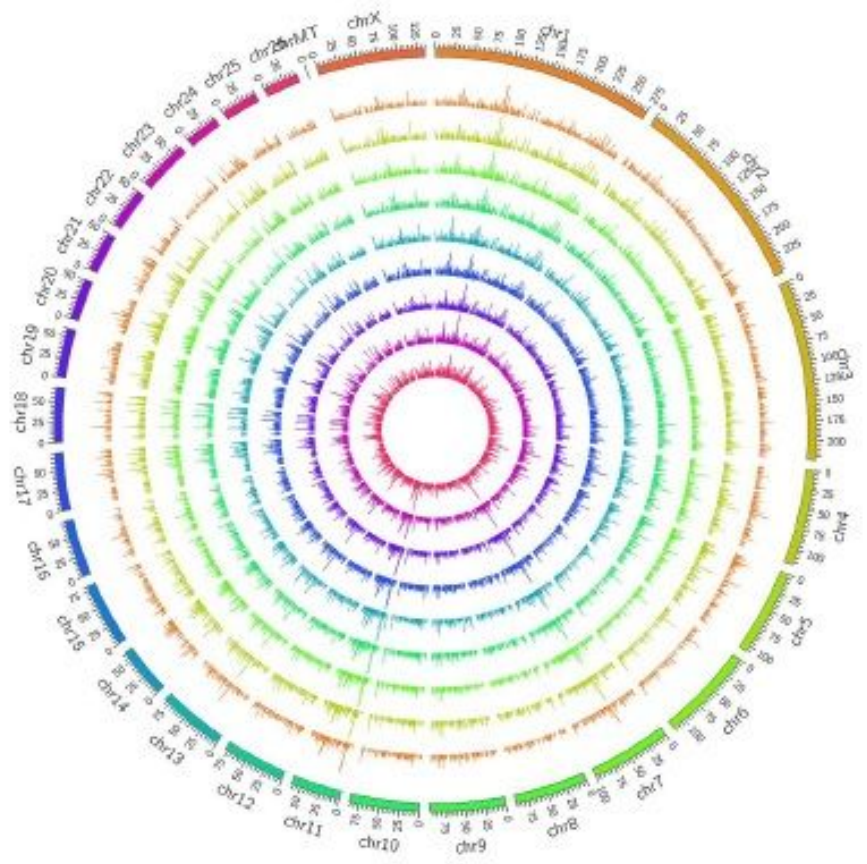

Figure 1

a. Classifcation of IncRNA :(i) a transcript falling entirely within a reference intron (intronic); (j) potentially novel isoform or fragment at least one splice junction is shared with a reference transcript; (o) generic exonic overlap with a reference transcript; (u) unknown, intergenic transcript (intergenic); (x) exonic overlap with reference on the opposite strand (antisense); (=) complete match, considered as known IncRNAs. b. The chromosome distribution of IncRNA. From outside to inside are samples 6M (1-3), 18M(1-3), 30M(1 -3). 


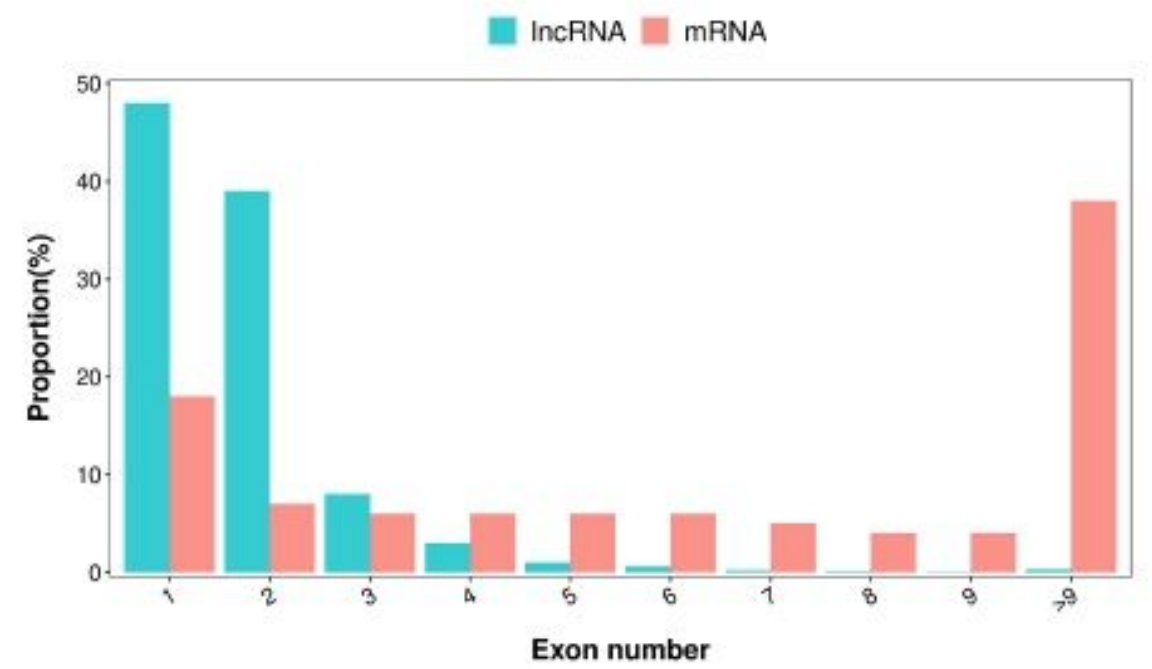

b

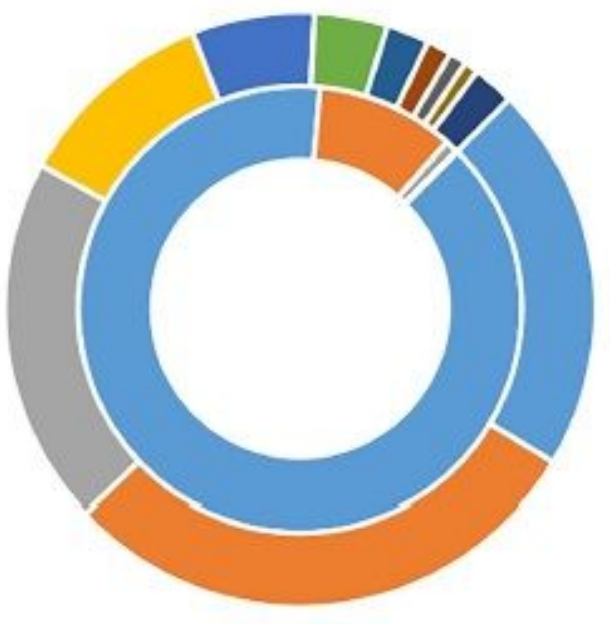
ㅁ. $0-200$
- $200-400$
- $400-600$
프 $600-800$
- 800-1000
- 1000-1200
- 1200-1400
- 1400-1600
- 1600-1800
- $1800-2000$
- $\geq 2000$

\section{ORF length(in aa)}

\section{Figure 2}

a. comparison of the number of exon in mRNAs and IncRNAs; b. comparison of the ORF length of mRNAs(outer) and IncRNAs(inner). 


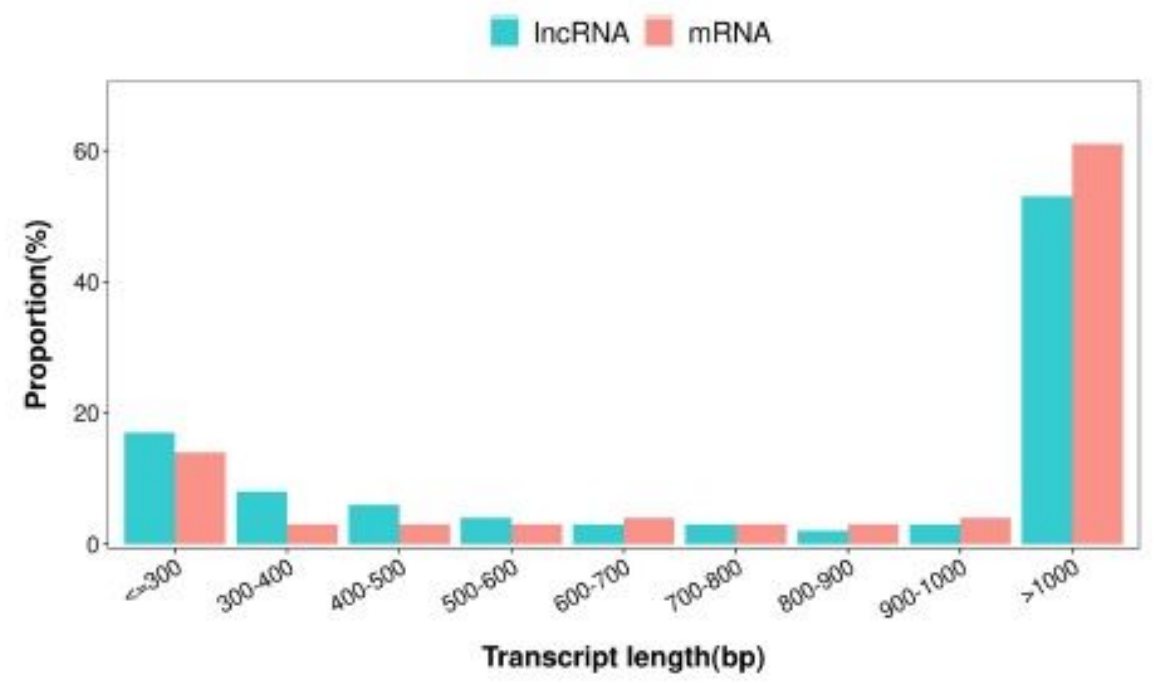

b
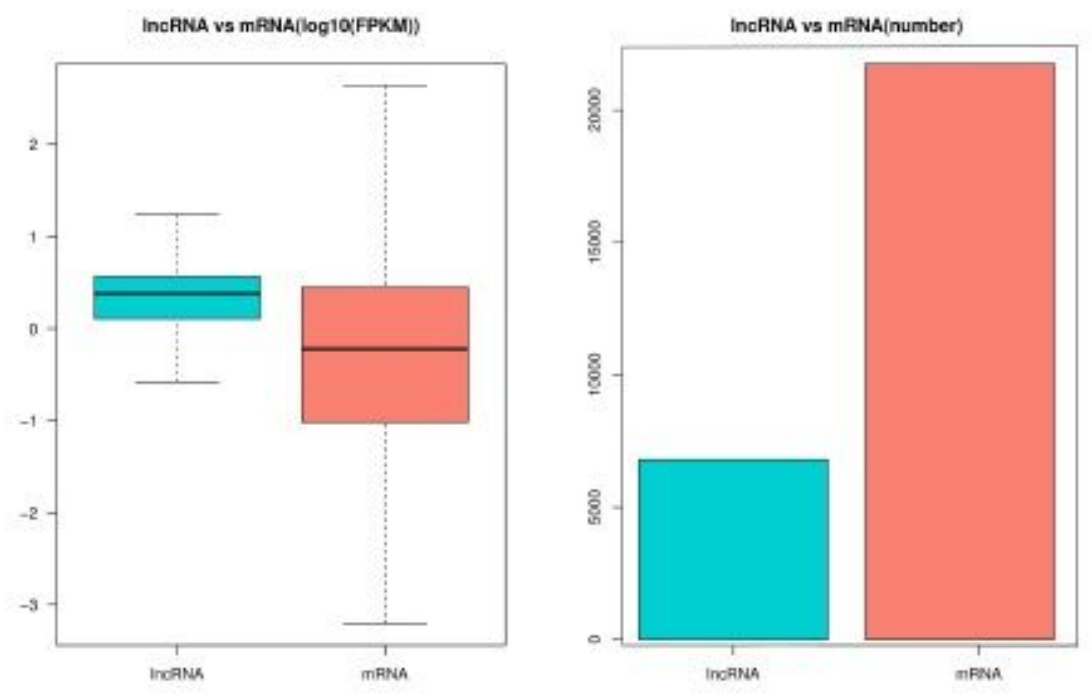

Figure 3

a. comparison of the transcript length of mRNAs and IncRNAs; b. comparison of the expression level and number of mRNAs and IncRNAs. 
a

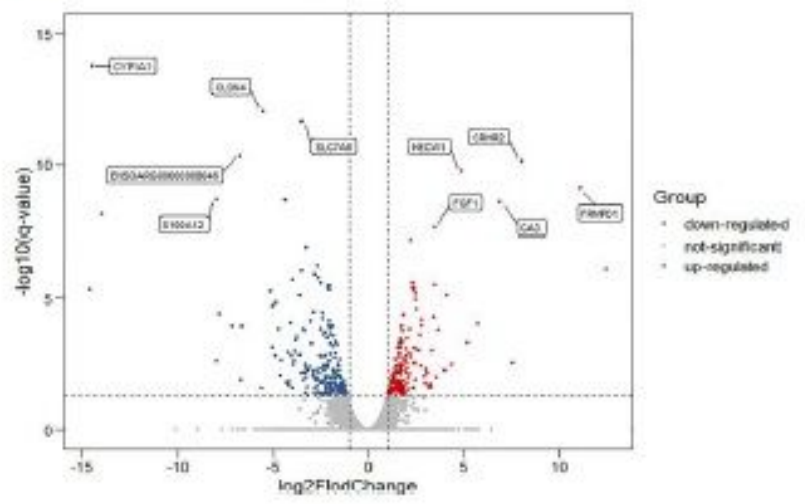

b

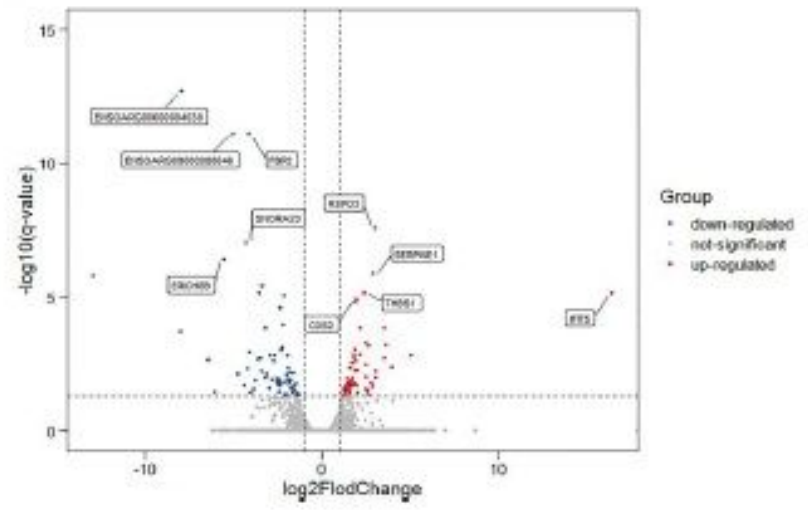

$\mathrm{C}$

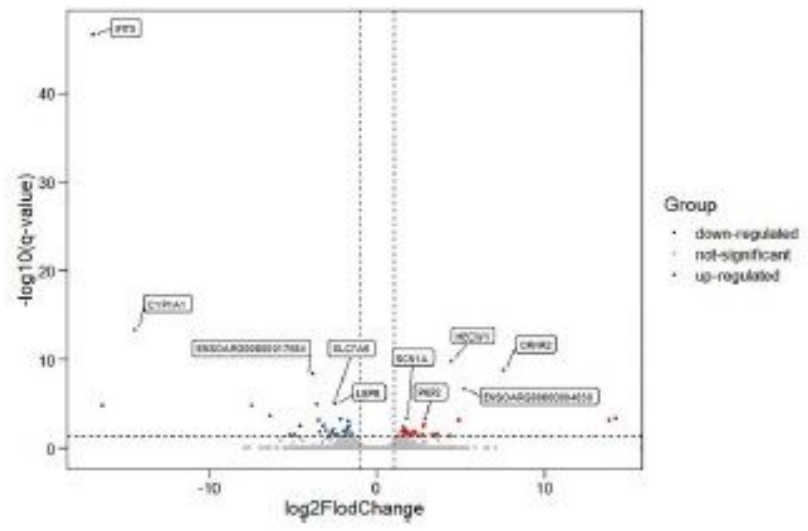

Figure 4

The volcano plot of DEGs. a: $30 \mathrm{M}$ vs $6 \mathrm{M}$; b: $30 \mathrm{M}$ vs $18 \mathrm{M}$; c: $18 \mathrm{M}$ vs $6 \mathrm{M}$. Annotated as the top five of the qvalue. 
a

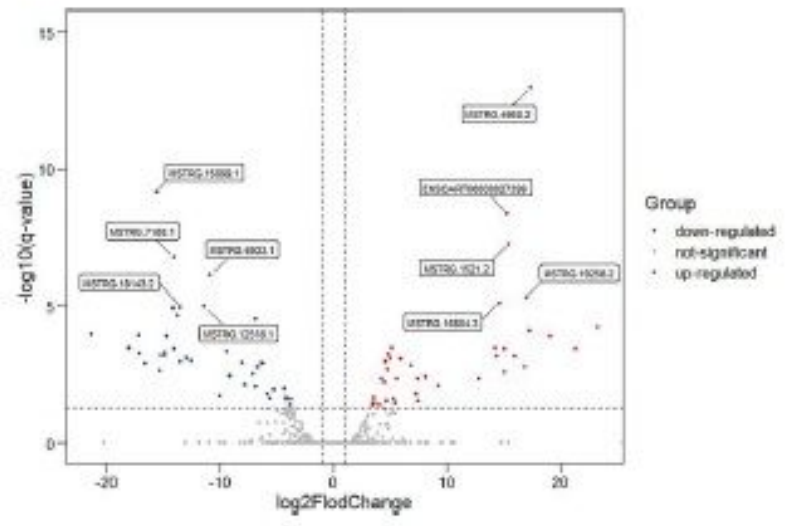

b

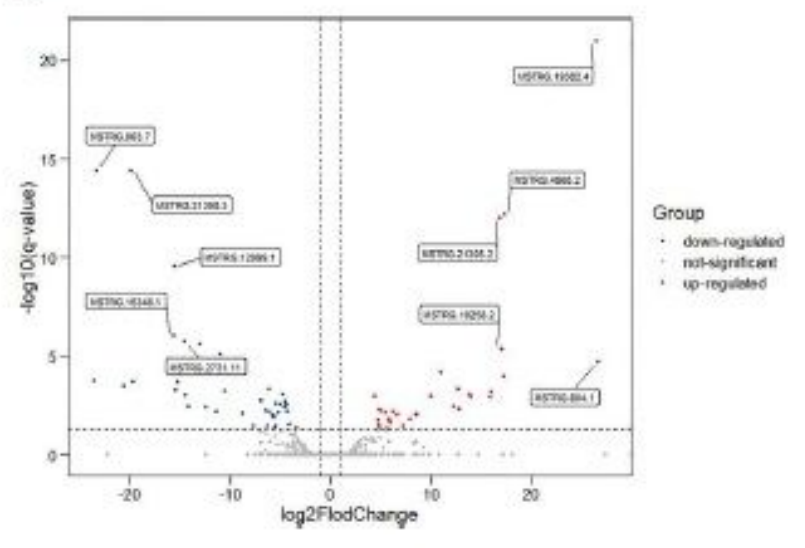

C

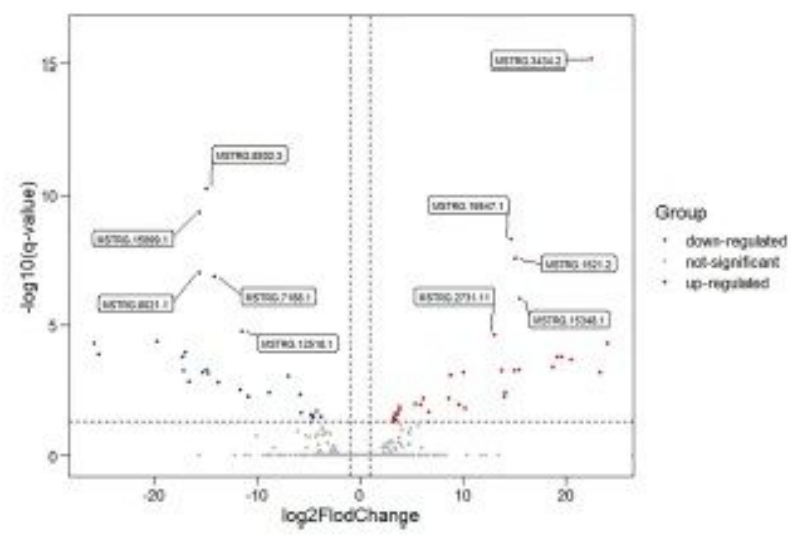

Figure 5

The volcano plot of DE IncRNAs. a: $30 \mathrm{M}$ vs $6 \mathrm{M} ; \mathrm{b}: 30 \mathrm{M}$ vs $18 \mathrm{M}$; c: $18 \mathrm{M}$ vs $6 \mathrm{M}$. Annotated as the top five of the q-value. 

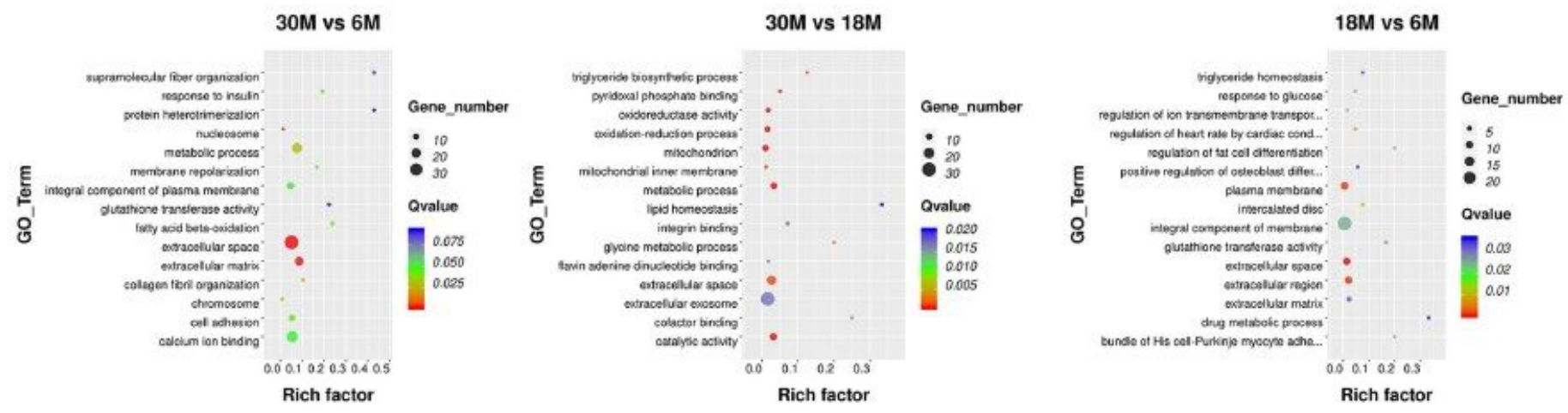

b
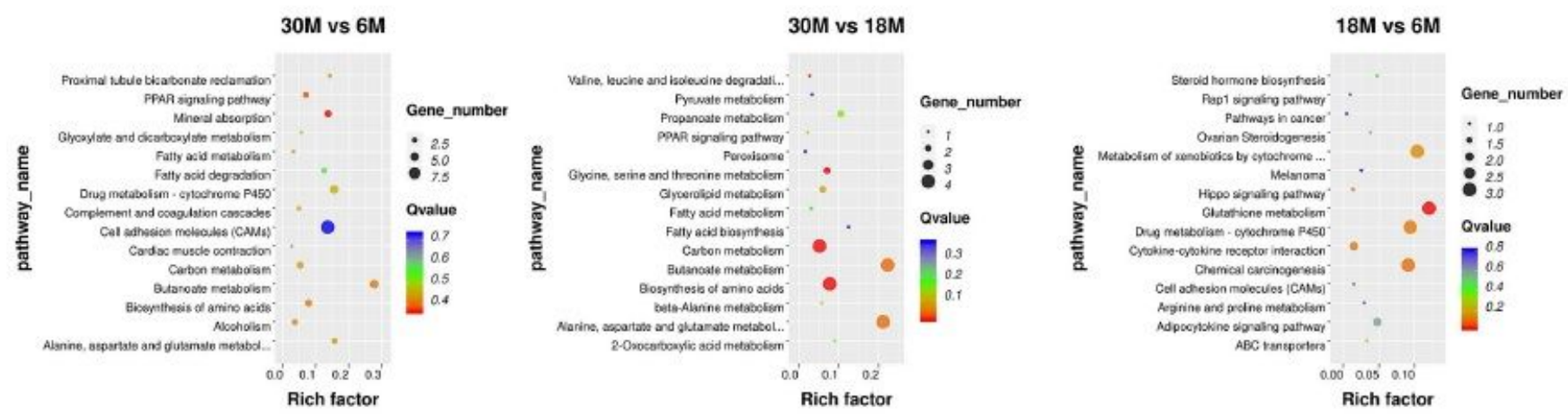

Figure 6

The top 15 GO and KEGG analysis of DEGs. a.GO analysis of three comparison groups; b. KEGG analysis of three comparison groups. 


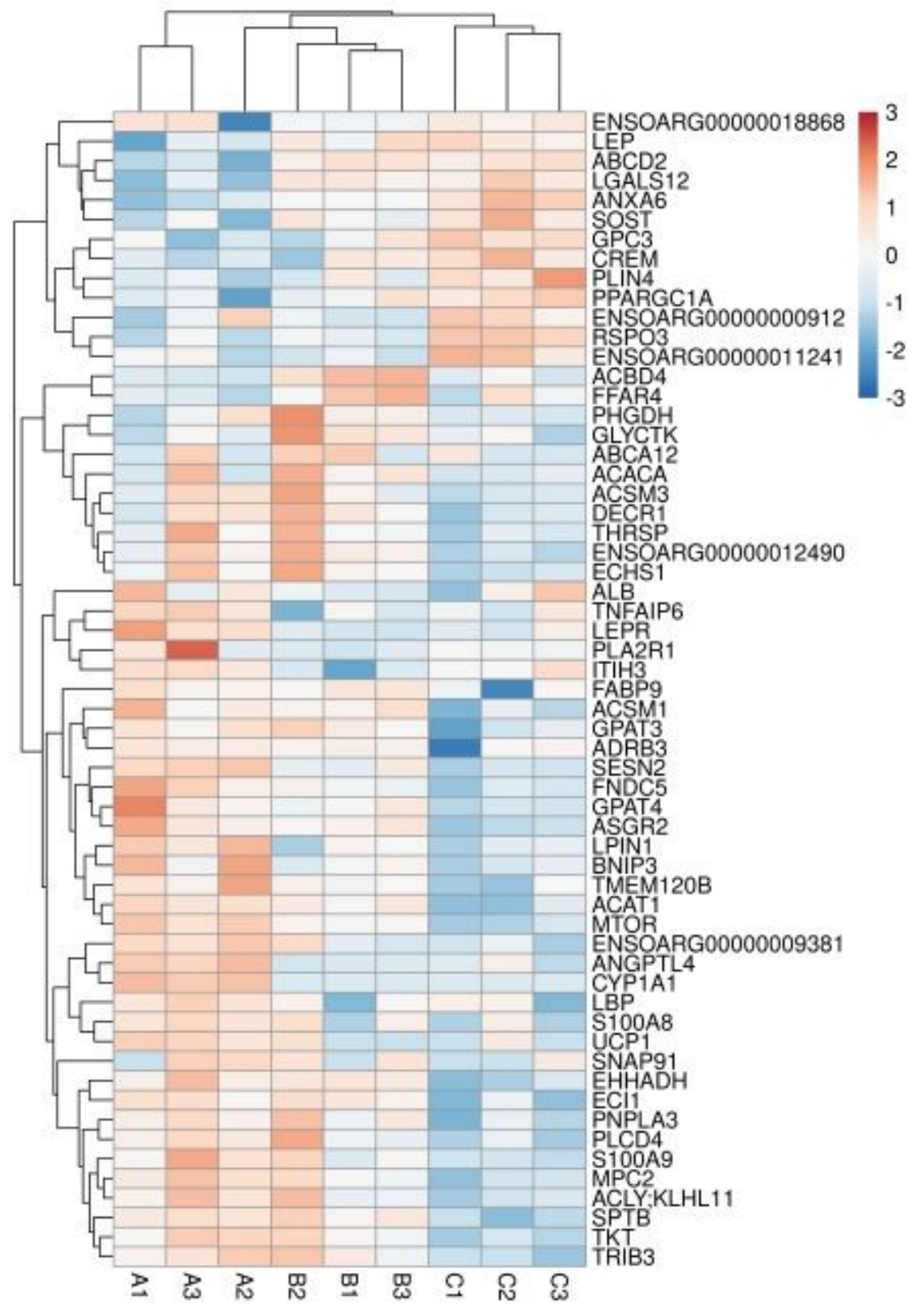

Figure 7

The top 15 GO and KEGG analysis of DEGs. a.GO analysis of three comparison groups; b. KEGG analysis of three comparison groups. 


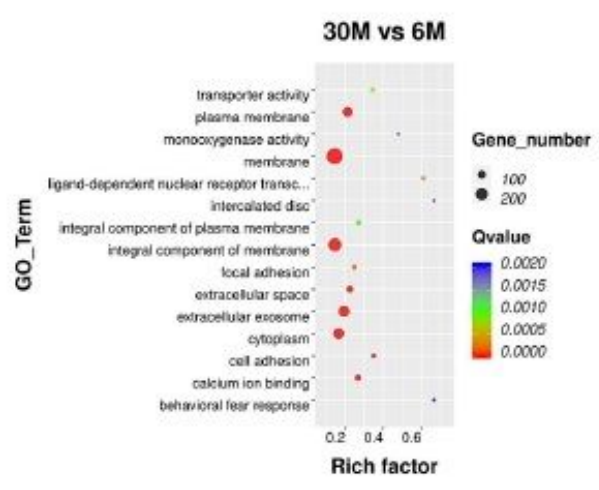

b

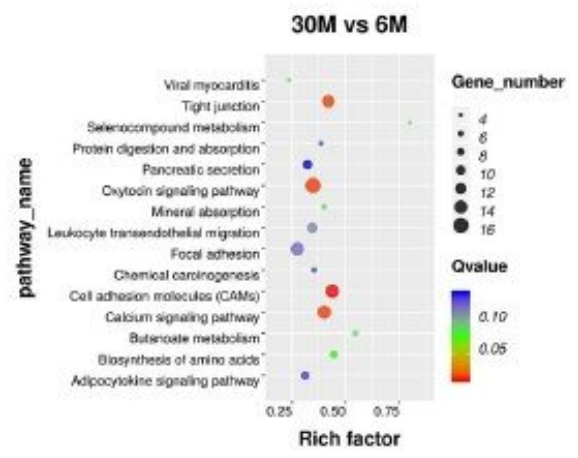

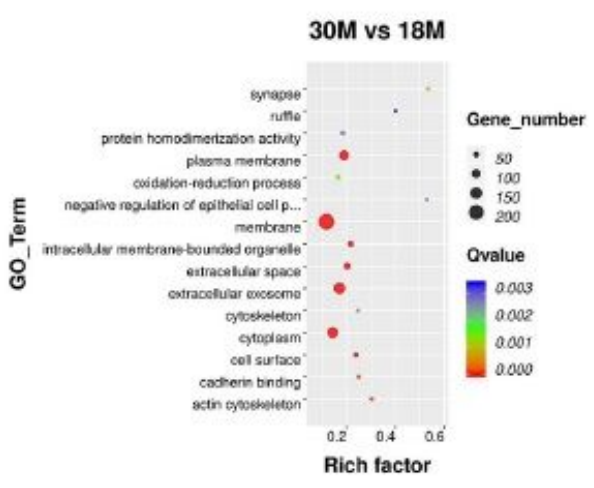

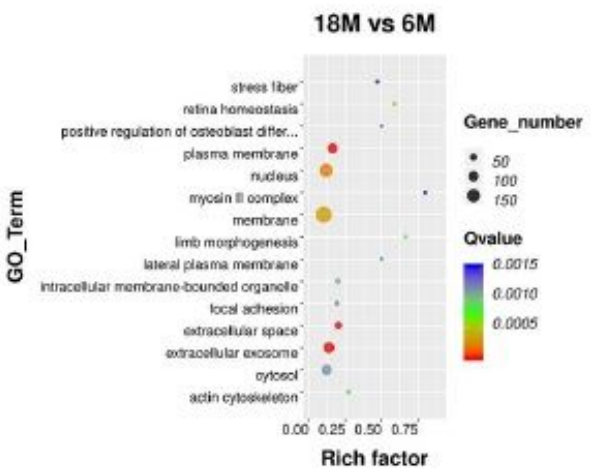

$30 \mathrm{M}$ vs $18 \mathrm{M}$

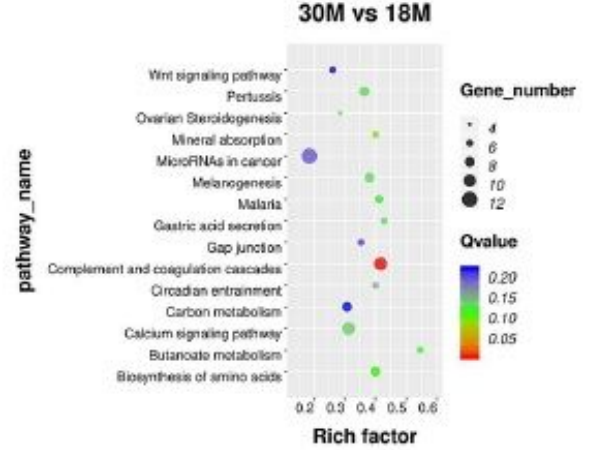

$18 \mathrm{M}$ vs $6 \mathrm{M}$

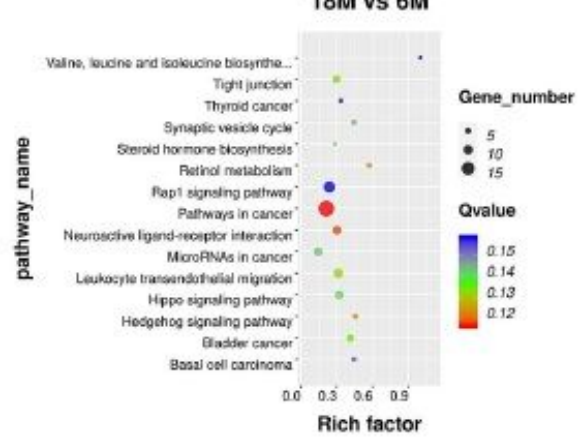

\section{Figure 8}

The top 15 GO and KEGG analysis of DE IncRNAs. a.GO analysis of three comparison groups; b. KEGG analysis of three comparison groups. 


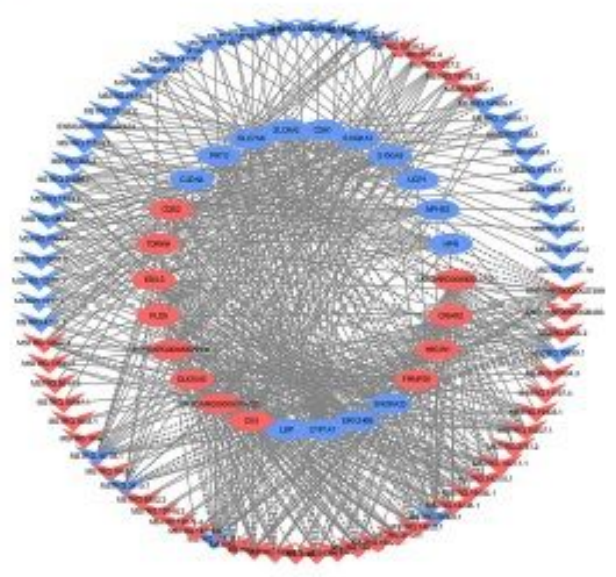

b

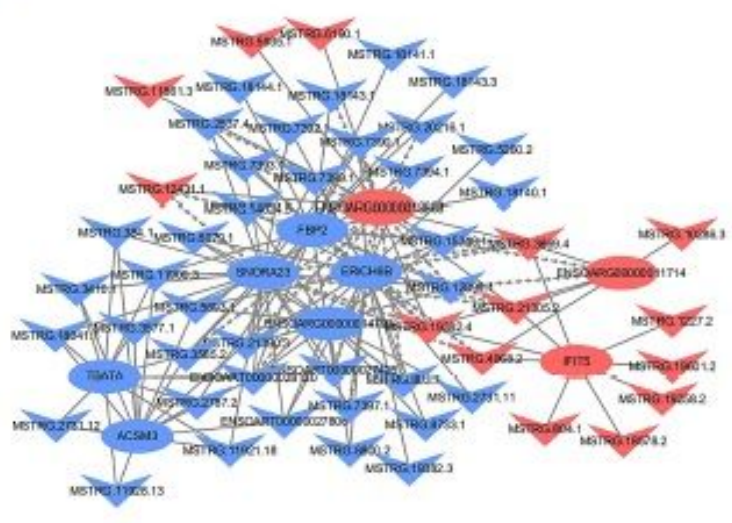

$\mathrm{C}$
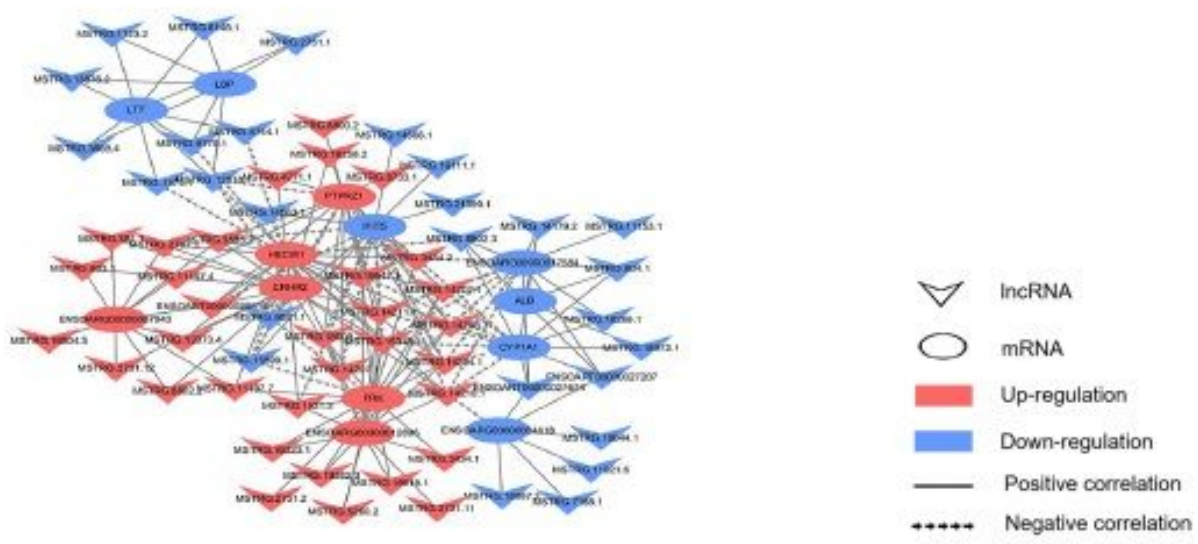

Figure 9

The co-expression network of $30 \mathrm{M}$ vs $6 \mathrm{M}(\mathrm{a}), 30 \mathrm{M}$ vs $18 \mathrm{M}(\mathrm{b})$, and $18 \mathrm{M}$ vs $6 \mathrm{M}(\mathrm{c})$. 